\title{
Hacia una gran colección de monedas antiguas en España. El padre Flórez y dos colaboradores desconocidos
}

Towards a great collection of ancient coins in Spain.

Padre Flórez and two unknown contributors

Antonio Mestre Sanchis

Universidad de Valencia

CES.XVIII, núm. 26 (2016), págs. 331-355 


\section{RESUMEN}

El objeto del artículo es demostrar, a través de los epistolarios privados, especialmente los conservados por Gregorio Mayans, que la Numismática fue objeto de especial interés entre los hombres de letras del siglo XVIII; perfilar la red cultural y política que impulsó los estudios de esta ciencia en España; delinear cómo se tomó conciencia de la necesidad de publicar una colección de monedas y desentrañar las circunstancias en que Flórez redactó su obra Medallas de las colonias, municipios y pueblos antiguos de España (1755-1773).

Palabras Clave

Enrique Flórez, Numismática, Gregorio Mayans, Agustín Sales, José Ríos, Alejandro Panel.

\section{Abstract}

The purpose of the article is to demonstrate, through private collected letters, especially those kept by Gregorio Mayans, that the Numismatic was a subject of special interest among the literati of the eighteenth century; outline the cultural and political network that drove the studies of this science in Spain; delineate how to became aware of the need for publishing a collection of coins and unravel the circumstances in which Flórez wrote his work Medallas de las colonias, municipios y pueblos antiguos de España (17551773).

KEYWORDS

Enrique Flórez, Numismatic, Gregorio Mayans, Agustin Sales, José Ríos, Alejandro Panel.

Recibido: 9 de enero de 2016. Aceptado: 28 de julio de 2016. 
Los últimos estudios sobre el siglo XVIII español han demostrado la fuerza renovadora del humanismo; y, por supuesto, ha quedado patente el error de quienes identificaban los estudios clásicos greco-latinos con la ratio studiorum de la Compañía, que, como tal, entrañaría el apoyo al tradicionalismo y una rémora al movimiento ilustrado.

Hubo, por supuesto, humanistas tradicionales. Pero también hubo espléndidos conocedores de las lenguas clásicas, opuestos a la pedagogía jesuítica. Baste recordar, en este sentido, las duras censuras de Manuel Martí, el deán de Alicante, o de Gregorio Mayans, que simbolizan la crítica de las pacatas lecturas de los clásicos propiciadas por los padres de la Compañía, al tiempo que aconsejaban el conocimiento de Terencio y de Lucrecio, autores mal vistos por la pedagogía jesuítica ${ }^{1}$. Al margen de las importantes diferencias entre Les Lumiéres y la Ilustración, también en Francia hubo buenos humanistas entre los philosophes (caso Diderot) y es notable la influencia del mundo clásico en muchos políticos y hombres de letras de la Revolución Francesa.

Ahora bien, conviene tener en cuenta que no todos los jesuitas se limitaban a la interpretación tradicional de la ratio studiorum, y a mediados de siglo aparecen padres de la Compañía abiertos a la interpretación clásica: un grupo en Cataluña en el entorno de Josep Finestres, otro en Castilla con vinculación al helenista Petisco (en Villagarcía) y el de Andrés M. Burriel en la Corte. Este movimiento adquiere fuerza en los círculos madrileños a mediados de siglo, tanto por la influencia de los padres de la Compañía, que ocupaban cargos en la administración político-cultural (confesor del rey) como por profesores de Alcalá, y, por supuesto, de Rodríguez Campomanes, «un helenista en el poder» en palabras de Luis $\mathrm{Gil}^{2}$.

Dicho esto, conviene recordar que el humanismo del siglo XVIII no olvidó el estudio de las «medallas» (monedas) e inscripciones antiguas que permitían el conocimiento directo y exacto del pasado. En la lucha contra los falsos cronico-

1 Puede verse el contraste de la visión de Martí con la de los padres de las Memoires de Trèvoux, en mi estudio preliminar a Gregorio MaYANS y SISCAR, Epistolario III. Mayans y Martí, edición preparada por A. Mestre Sanchis, Valencia, Ayuntamiento de Oliva, 1973. Y, en el conjunto español, Antonio Mestre Sanchis, Humanistas, políticos e ilustrados, Alicante, Universidad de Alicante, 2003.

2 Luis GiL, Pedro Rodríguez de Campomanes, un humanista en el poder, Madrid, FuE, 1976. 
nes y falsificaciones históricas, según de Helena Garrido, «en esta confusión, el recurso a la Numismática, pero sobre todo a la Epigrafía, desde el inicio había sido esencial como testimonio de la veritas ${ }^{3}$. Y la misma H. Garrido, basándose en los trabajos de Peset, L. Abad y J. M. Abascal y A. Mestre, estudia la aportación de Mayans al estudio de la Epigrafía.

No pretendo analizar las aportaciones de Mayans a la Numismática, ni por supuesto, exaltar o limitar los méritos del P. Flórez en Medallas de las colonias, municipios y pueblos antiguos de España $a^{4}$. Mi intención es muy distinta. Pretendo señalar el interés generalizado en la España del XVIII por las monedas antiguas. Debo confesar, desde el primer momento, que no soy un experto en la historia de la Numismática. Pero la lectura de muchos millares de cartas de los hombres de letras del siglo XVIII me permite asegurar que el intento de adquirir y coleccionar monedas antiguas fue una preocupación muy generalizada. Flórez participó de ese interés por las monedas antiguas y encontró comprensión y aportaciones, entre otros, de Agustín Sales, cronista de la ciudad y reino de Valencia, y de José Ríos, cura de Cullera. La abundante correspondencia conservada por Gregorio Mayans nos permitirá una aproximación al conocimiento de los hechos.

No sólo había interés por coleccionar monedas antiguas. Más aún, era una idea generalizada la necesidad de publicar una buena colección de monedas, que viniera a completar la obra de Antonio Agustín, iniciador de la Numismática moderna. Valgan las palabras de Mayans como expresión de esa necesidad; así se expresaba el erudito de Oliva en la prefación a las Obras chronológicas del marqués de Mondéjar: «También deseo yo que se haga una semejante Colección de Medallas; porque don Antonio Agustín más autorizó i ennobleció el estudio de las medallas que explicó lo mucho que en ellas ai, especialmente en lo que toca a las cosas de España» ${ }^{5}$. Y añade dos matices: semejante estudio era despreciado en la época del arzobispo de Tarragona, y lamenta la interpretación de las monedas que hizo el padre Juan Harduin. Indico esta última advertencia, porque ahí radica una de las claves de su antipatía por los proyectos del P. Panel.

Que el P. Burriel estaba detrás del movimiento a favor de los estudios de Numismática era conocido por los interesados. Así se expresaba el biblioteca-

3 Helena Gimeno Pascual, «Avances y retrocesos de una disciplina: ilustrados españoles ante la epigrafía», en Illuminismo e Ilustración. Le antichità e i loro protagonisti in Spagna e in Italia en XVIII secolo, Roma, L'Erma di Bretschneider, 2003, págs. 183-200.

4 Tomos I y II: Madrid, Oficina de Antonio Marín, 1757 y 1758; Tomo III: Madrid, Imprenta de Antonio Sancha, 1777.

5 G. Mayans y siscar, Obras completas. I Historia, edición preparada por A. Mestre Sanchis, Valencia, Ayuntamiento de Oliva, 1983, pág. 47. 
rio real Martínez Pingarrón, encargado del monetario de la Real Biblioteca, en carta a Mayans: «Advierto que (Velázquez Velasco) es íntimo, intimíssimo del P. Burriel i del P. Flórez» ${ }^{6}$. Esa amistad de Velázquez con el P. Flórez está confirmada por el P. Méndez en su Vida, escritos y viajes del Rmo. P. Mto. Fr. Enrique Flórez ${ }^{7}$. La amistad era bien conocida por las frecuentes visitas de Velázquez al monetario del agustino y se rompió, a juicio de Méndez, por la ingratitud del autor del Ensayo, que no citó a Flórez en su obra. Por lo demás, tampoco el autor de la España sagrada fue muy agradecido a los favores de los jesuitas Burriel y Rávago.

Como no voy a estudiar el caso de Velázquez y su Ensayo sobre los alphabetos de las letras desconocidas que se encuentran en las más antiguas medallas y monumentos de España (1752), conviene señalar la procedencia del favor que alcanzaron Velázquez y Flórez del P. Confesor, el jesuita Rávago (con el favor de Burriel, en el fondo), en apoyo o subvenciones económicas. El mismo Pingarrón escribía: «El Padre (Rávago) tiene dicho que desea se promueva tal estudio, pero es gran político i mui cortesano...» (10-II-1753). Rávago confesaba que ignoraba esa ciencia, era un teólogo escolástico y no había «leído libro alguno francés», según Pingarrón había dicho al mismo Velázquez. Como es conocido, a Velázquez le fue retirada la subvención económica, con la caída de Ensenada y la exoneración de Rávago, si bien le fue continuada a Flórez por los manteístas.

También obtuvo el favor y comprensión de Burriel otro jesuita, el francés Alejandro Panel, aunque sus proyectos no acabaron de cristalizar. Y, por supuesto, el apoyo económico a los estudiosos de la Numismática vino de los políticos: del grupo francés del gobierno de Felipe $\mathrm{V}$ en el caso de Panel, de Ensenada en el caso de Velázquez y de los manteístas en el del P. Flórez.

\section{El jesuita francés Alejandro Panel}

Era Panel un jesuita francés, («aforrado de si mismo», en correspondencia confidencial entre Burriel y Mayans) que, protegido por el P. Confesor real, P. Guillermo Clarke (también jesuita), vino a España como preceptor del infante don Luis, arzobispo-cardenal de Toledo, y encargado de organizar el museo numismático del hijo de Felipe V.

6 Martínez Pingarrón a Mayans, 25-XI-1752, en MaYans y Siscar, Epistolario VII, Ayuntamiento de Oliva, 1987. Todas las citas de la correspondencia se hallan en los volúmenes del Epistolario VII, VIII y IX.

Utilizo la segunda edición de Madrid, 1860. 
En 1743 llegó Panel a Valencia y encontró buena acogida en el arzobispo Mayoral y, sobre todo, por parte de Pérez Bayer. «Avrá como 8 días que estuvo acá un padre de la Compañía, francés, que desembarcó aquí y ha passado a Madrid por anticuario del rey a arreglar la serie numismática al Infante Dn. Phelipe. Llámase Alexandro Xavier Panel; es de 38 años, muy suelto en el latín, pero no me parece igualmente culto, aun quitada la aspereza natural en la pronunciación. Vio mis monedas, el amo le combidó a ver la processión y le agasajó mucho» ${ }^{8}$. De hecho, Bayer cultivó la amistad de Panel que lo puso en relación con el nuevo confesor (el francés Le Fèvre) y de su benevolencia — junto con el favor de los colegiales (Villafañe y del obispo de Salamanca) — consiguió la cátedra de hebreo de la Universidad salmantina y después el nombramiento de investigador en la Comisión de Archivos y colaborador de Andrés Marcos Burriel.

En contraste, el grupo de amigos de Mayans manifestó su recelo ante la actitud de Panel y su interés por conseguir monedas antiguas. Agustín Sales avisaba al erudito, retirado en Oliva, de la presencia del jesuita francés, así como de su interés por ver y adquirir monedas antiguas. Y, dado que Mayans poseía el mejor monetario, debía estar prevenido ante la visita de Panel. Más aún, Sales comunicaba al erudito que Pasqual Escrivá, el Presidente de la Academia Valenciana, a quien Mayans había prestado un buen lote de monedas, había marchado a Madrid y conectado con Panel. La noticia era clarificadora. Escrivá alababa mucho a Panel: «Mi sentir es que el P. Panel desea dibujos de las medallas de colonias i municipios, i es preciso Vm. saque las suyas de Dn. Pasqual, porque peligra que se las embíe dibujadas (21-VIII-1743).

Sin embargo, la solicitud de relacionar a Mayans con Panel vino de Burriel. Este, que apreciaba sinceramente al erudito, deseaba que escribiera una historia de la catedral de Toledo, y tenía convencido al deán de la catedral primada (Juan Antonio de las Infantas). Pero, dada la envergadura de la empresa y los gastos requeridos, no podía llevarse a cabo sin la decisión expresa del prelado, el cardenal-infante don Luis, cuyo preceptor era Panel. El intento no prosperó, y el mismo Burriel llegó a la convicción de que Panel (que convivía en la misma residencia) no tenía consistencia personal para apoyar la empresa.

Conocemos una anécdota que revela el trasfondo de los intereses por la Numismática. Aquejado de una fuerte hemotisis, Burriel residió unos meses en su pueblo natal, Buenache de Alarcón, y consiguió un buen número de monedas antiguas, que describe con minuciosidad. Entre los documentos, envía a Mayans, «además cinco papeles con varias monedas: 5 de plata, 16 recogidas

8 Pérez Bayer a Mayans, 19-VI-1743, en G. Mayans y Siscar, Epistolario VI. Mayans y Pérez Bayer, edición preparada por A. Mestre Sanchis, Ayuntamiento de Oliva, 1977. 
en Toledo, 14 en Buenache halladas algunas este año cabando; 8 en Valera y Almodóvar: 5 incógnitas españolas de bronce» ${ }^{9}$. Con alegría envió ese pequeño tesoro a su amigo don Gregorio. Se trataba de una posible solicitud de información, o simplemente de un acto de delicadeza; porque, pasado un tiempo, el joven jesuita solicitó la devolución de las monedas, con una precisión: «Espero la carta de Vmd. para mi Santiago (Palomares) cuya habilidad y calidades me alegro merezcan a Vmd. el mismo aprecio y cariño que a mí. Embiaré a Valencia por las monedas que no corrían prisa. Yo no las quiero para embiarlas al P. Panel, porque yo no tengo comercio con él», aunque sí quería demostrar al jesuita francés su interés personal por la numismática. (18-VII-1745).

Burriel había descubierto la animosidad de Panel contra Mayans, y sospechaba con fundamento que su origen radicaba en la influencia de Miguel Herrero, que había conseguido el nombramiento de cronista de Indias en 1734, plaza que solicitó y deseaba Mayans. Burriel, que vivía en la misma residencia de Panel, comunicaba noticias al erudito: Panel solicitó inscripciones de Valencia, dejó el cargo de preceptor del Cardenal-Infante (porque este, como simple clérigo, se había secularizado) y se preocupaba exclusivamente de monedas, y en algún momento hablaba de la cantidad de monedas que poseía Panel... Pero tenemos un texto clarificador. En 1751, Panel solicitó de los valencianos el envío de monedas antiguas. Y don Gregorio, que conoció la noticia, se valió de su íntimo Juan Bautista Cabrera para disuadir a sus amigos, porque no era justo favorecer a «un malvado e ignorante..., porque yo no estoi para perder tiempo por los que no conozco, i menos para escrivir una carta al que habló contra mí al Confesor passado del rei» ${ }^{10}$. He aquí las clarificadoras palabras de Juan Antonio al margen: «el P. Panel», al «P. Le Févre, a quien dijo Panel que Mayans era enemigo de la Compañía, motivo por el qual no fueron recompensados sus grandes méritos. El mismo embarazo halló de parte del P. Rávago» ${ }^{11}$.

Ahora bien, ¿̨hubo, además, relación directa entre Panel y Mayans, que permita esclarecer esos juicios? No hay duda de que hubo intercambio de correspondencia. El 14 de julio de 1761, Pingarrón indicaba al erudito de Oliva que, junto a su carta personal, encontraría otra de Panel. La carta del jesuita francés, de que habla el bibliotecario real, era la respuesta a la de Mayans del 21 de julio anterior en que le envió las adiciones del mismo Sánchez de las Brozas a la Minerva. Las había encontrado un amigo y el erudito, que poseía dos copias, envió una al conde de Lynden, que las publicó en la sexta edición de

9 A. M. Burriel a Mayans, 6-VI-1745. Todas las cartas Burriel-Mayans en Epistolario de Mayans, vol. II, preparado por A. Mestre Sanchis, Ayuntamiento de Oliva, 1972.

10 G. Mayans a J. B. Cabrera, 17-I-1750, BAHM, 120.

11 Textos en mi «Estudio Preliminar» al Epistolario Mayans. Burriel, pág. XXV. 
la Minerva (1754); y envió la otra copia a Panel, al tiempo que le avisaba de la próxima aparición de las inscripciones latinas halladas en Cataluña preparadas por Joseph Finestres.

No encontré las cartas de Panel al erudito, pero sí dos de Mayans al jesuita francés muy interesantes. Y, leídas con atención, dentro de las formalidades habituales, hay en ellas una evidente crítica, tanto de Panel, como de su entorno. La primera es del 29 de julio de 1758; y el inicio indica el marco de las diferencias: «Ya que otros no han querido complacer a V. S. Rma., yo le serviré de buena gana; i en mi pronta obediencia mostraré que no soi enemigo de la Sociedad, como parece que algunos de intención maligna han querido persuadir a V.S. Rma.». Por lo demás, la carta constituye una historia, bien documentada, de los orígenes de las corridas de toros.

Con toda certeza Panel respondió al erudito, alabando su erudición y, por el contexto de la respuesta de Mayans (26-VIII-1758), parece que el jesuita francés se unió a los deseos de su compañero Burriel de que el valenciano trasladara su residencia a la Corte con la perspectiva de algún cargo ${ }^{12}$. Y don Gregorio aprovechó la ocasión para explayarse. Confiesa excesivos los elogios de Panel a su carta, «que pudieran desvanecerme, si yo no me conociera bien». Mayans señala que ya conocía el mérito de Panel pues, antes de abandonar la Real Biblioteca, el P. Clarke le había enseñado unos «epigramas» suyos y le confió la intención de invitarlo a España. «Pero lo que me obliga a dar a V. S. Rma. especialíssimas gracias, es el favor de querer intentar, de motivo propio, que buelva yo a la Corte». Era la ocasión, y Mayans la aprovechó, para explicar por qué abandonó la Real Biblioteca (fracaso de la solicitud de cronista de Indias, que consiguió Miguel Herrero, que estaba en el círculo de Panel) y las presiones familiares, los trabajos secretos que hizo para el P. Confesor, Le Fèvre, que, ignorados, no fueron premiados... Si hubiera estado Panel junto a Le Fèvre, y le hubieran ofrecido entonces un buen empleo... ¿Era una velada crítica a la mala reputación que, según confiesa en correos confidenciales, le puso Panel al P. Confesor?

Pero ahora confiesa, «aquí estoi bien hallado, pues mis conveniencias heredadas de mis mayores son suficientes para mantenerme con decencia». Escribe libros, aunque muchos permanecen manuscritos, mantiene correspondencia con hombres de letras españoles y europeos, posee una espléndida biblioteca $\mathrm{y}$, además, tiene una familia numerosa que no aconseja un traslado de futuro incierto. En el fondo, venía a ser una apología personal y una crítica a quienes, teniendo poder (ministros o padres Confesores) no habían querido favorecerle.

\footnotetext{
12 Las tres cartas de Mayans a Panel se encuentran en BAHM, 159.
} 
Por lo demás, conviene tener presente que tampoco Panel fue generoso con Flórez, a quien no dejó ver sus monedas: «Panel guarda mucho sus caudales. Si entre los divujos de mis medallas hay alguno de copia hecha aí para su colección, no es por haver visto sus divujos (pues nunca ha querido mostrármelos), sino por existir los originales en mi estudio. Si en essa línea de colonias y municipios de España tuviere Vmd. algo inédito, le estimaré la noticia» ${ }^{13}$.

\section{El interés del P. Flórez por la Numismática}

Entre las obras del P. Enrique Flórez sobresale, y con razón, la España sagrada, donde el agustino — en numerosos volúmenes_ dio su criterio sobre la historia eclesiástica española. Pero Flórez escribió otras obras, desde un Cursus theologicus (1732) hasta Medallas de las colonias, municipios y pueblos antiguos de España (3 vols., 1757-1773).

No hay duda de que Flórez tuvo colaboradores (como recientemente se ha demostrado $)^{14}$, para redactar tantos volúmenes sobre los orígenes y evolución de las diócesis hispanas. Pues bien, asimismo tuvo colaboradores en la redacción de las Medallas de las colonias, municipios y pueblos antiguos de España... y el mismo agustino lo confiesa en el volumen primero, con el título de Gabinetes de que el autor se ha servido fuera de sus medallas, y de las publicaciones en diferentes lugares. Pues bien, entre los propietarios de esos gabinetes aparecen dos personajes: el poco conocido Agustín Sales y el prácticamente desconocido José Ríos.

Por lo demás, es evidente que Flórez participaba del interés generalizado por la numismática. Los datos que aporta el P. Méndez en la citada biografía constituyen un testimonio inapelable. Y, para un estudioso de Mayans, no puede sorprender la correspondencia del agustino con Pedro L. Villacevallos, que mantuvo un interesante intercambio de noticias con Mayans sobre Numismática. Un juicio de Juan Antonio, el hermano del erudito, es extraordinariamente elogioso de la riqueza del monetario de Villacevallos ${ }^{15}$.

El 9 de abril de 1746, el bibliotecario real M. Martínez Pingarrón daba noticias a Mayans de la persona y obra del padre agustino Enrique Flórez. Explicaba el bibliotecario real la evolución intelectual del agustino: inició sus pu-

\footnotetext{
13 Flórez a Sales, 29-VI-1754, pág. 577.

14 Una visión general en A. Mestre SAnchis, Historia, fueros y actitudes políticas. Mayans y la historiografía del siglo XVIII, Valencia, Ayuntamiento de Oliva, 1970.

15 A. Mestre, Correspondencia de los ilustrados andaluces, Sevilla 1990, págs. 386-414. En BaHм, 309, se conserva el testimonio de Juan Antonio sobre el monetario de Villacevallos, y trascribo en pág. 441.
} 
blicaciones con un Cursus theologicus en 5 vols. (1732). «Creo no tiene más que escrivir sobre este asunto. Está dedicado a escrivir de historia i antigüedades de España. Tiene más de dos mil medallas, muchas de ellas mui raras, algunas inéditas. Tengo amistad con él».

Quede constancia, desde el primer momento, de que las palabras de Pingarrón distinguen con claridad los dos aspectos que constituyen la aportación de Flórez en el campo de la historiografía: historia eclesiástica y numismática. Y aunque los dos aspectos se entrecruzan y aparecen en las siguientes páginas, la novedad radica, sobre todo en la numismática que, de hecho, constituye el campo menos estudiado de la actividad intelectual de Flórez, a pesar de las valiosas aportaciones del P. Miguélez ${ }^{16}$, que dedica una serie de artículos a estudiar el valor de la obra numismática de Flórez. Señala, por supuesto, el especial mérito de la España sagrada pero, al referirse al trabajo numismático, después de un breve análisis de los orígenes en Antonio Agustín y las aportaciones de extranjeros y de los españoles del siglo XVI, insiste en su decadencia en el siglo XVII en España. Respecto a la obra de Flórez, valora muy positivamente su aportación: «abrió una nueva época en las disquisiciones anticuarias, derramando a torrentes la luz en los descubrimientos numismáticos en nuestra península» (pág. 466); y continúa: «es todavía oráculo de los amantes de la antigüedad, y es consultada con admiración y respeto y no puede darse un paso seguro en numismática sin su consulta». Son palabras escritas en 1887. Mi intención, en estas páginas, es aportar un poco de luz para el conocimiento de las circunstancias en que el P. Flórez redactó su obra Medallas de las colonias...

Como vimos por el testimonio de Pingarrón, el interés de Flórez por la Numismática era conocido. Más aún, en abril de 1746, fecha de la citada carta de Pingarrón, Mayans ya había iniciado su correspondencia personal con el agustino, y sabía, por confesión de Flórez, de su interés por la Numismática y de la gran cantidad de monedas antiguas que poseía; porque el 4 de marzo anterior, Flórez escribía una atenta carta al erudito de Oliva: había leído la Oración, pronunciada en la Academia Valenciana por el pavorde Asensio Sales y, creyendo que el verdadero autor era Mayans (como efectivamente lo era), preguntaba al erudito sobre el juicio negativo acerca de la División de obispados atribuida al rey Wamba. Y don Gregorio había contestado explicando las razones en que basaba su criterio.

Dada la declarada amistad con Flórez, Martínez Pingarrón fue proporcionando noticias de la actividad intelectual del agustino: la edición de las Obras

16 Fr. M. Fraile Miguélez, «El P. Flórez y la numismática española», en La ciudad de Dios, XIV (1887), págs. 466-479, 542-551, 614-621, 691-703. 
de la Madre Ceo, llevada a cabo por Flórez (con interés de callar su participación por no desmerecer) y que el bibliotecario real aprobó por compromiso; el regreso del agustino a la corte y la decisión — confesada por el mismo Flórezde atacar la teoría sobre la Era Hispánica, expuesta por Mayans en la prefación a las Obras chronológicas de Mondéjar (1744). También Flórez había comunicado esa intención al bibliotecario mayor del rey, Blas Antonio Nasarre, que, en palabras de Pingarrón a Mayans, «está por Vmd. siempre y que este padre (según Nasarre) es un dotorelo» (22-VII-1747). Por lo demás, afirmaba Pingarrón que el agustino no era muy bien visto en la Real Biblioteca: «Estoi leyendo la obra de este P. Flórez. En lo que he visto en ella hasta ahora me parece que el padre escrive deprisa i sin aver reflexionado mucho. No puedo hablar del tomo segundo (de la España sagrada) porque no he hecho más que leer salpicando. Esté Vmd. seguro de que en la bibliotheca no tiene partido el frayle i que Dn. Blas de Nassarre i los de su conversación sienten mui mal de esta obra; i Nassarre me dice con toda seriedad diga a Vmd. que le ayudará en quanto Vmd. gustare. Todos esperan que Vmd. le impugne, i que no sea con ocasión de otra obra» ${ }^{17}$. Es bien sabido que Mayans no respondió en público a esas censuras de Flórez.

No hay duda de que personalmente Pingarrón no valoraba mucho la obra histórica de Flórez, y en concreto la Clave historial: «Ya avrá Vmd. visto el Curso theológico de este fraile i su Clave historial, por donde se puede hacer juicio de el autor i donde se advierten algunas erraduras, i pudiera avernos dicho se avía servido para ella del abad de Vallemont, o por mejor decir, que le avía copiado, pues Vallemont trae mucho más i mejor con mui excesivas ventajas» (9-VIII1747). Y, por supuesto, tampoco confiaba mucho en la honradez científica, o en su gratitud respecto a quienes le aportaban noticias. Porque, cuando en 1762, supo que el agustino proyectaba viajar a Valencia, escribió estas palabras al erudito de Oliva: «Prevengo a Vmd. de antemano para su gobierno que el P. Fr. Enrique Flórez está para hacer un viage a Valencia i Cathaluña, i discurro volverá por Aragón. Dice que en busca de piedras naturales para formar o perficionar su museo. Dios sabe a lo que va. Hace el viage por su gusto (a lo menos no sé otra cosa). Abra Vmd. el ojo, que yo no creo en frayles, i mucho menos en éste» ${ }^{18}$.

Por supuesto, no intento estudiar las relaciones de Flórez con Mayans, su colaboración y sus divergencias, que analicé minuciosamente en Historia, fueros y actitudes políticas. Mayans y la historiografía del XVIII (1970). Entre las

\footnotetext{
17 Martínez Pingarrón a G. Mayans, 21-X-1747, en G. Mayans y SISCAR, Epistolario VII. Mayans y Martínez Pingarrón, 1. Historia cultural de la Real Biblioteca. Edición preparada por A. Mestre Sanchis, Valencia, Ayuntamiento de Oliva, 1987.

18 23-III-1762, G. Mayans y Siscar, Epistolario VIII, 2. Los manteístas y la cultura ilustrada. Edición preparada por A. Mestre Sanchis, 1988.
} 
coincidencias, el criterio sobre la falsa División de obispados atribuida al rey Wamba, en que Flórez repite el criterio de Mayans que el agustino conocía bien, gracias al volumen manuscrito que le facilitó Juan Antonio, el hermano del erudito. Las diferencias, las tradiciones eclesiásticas: así, mientras Flórez defendía con calor la venida de Santiago a España, la tradición de la Virgen del Pilar o los varones apostólicos, el erudito de Oliva les negaba toda validez histórica por carecer de pruebas documentales.

\section{Los colaboradores de Flórez en el estudio de la Numismática}

Pudimos observar que Pingarrón, en la citada carta del 9 de abril de 1746, especificaba dos facetas en los trabajos históricos de Flórez: la historia eclesiástica y la numismática. Ahora bien, mientras en el campo estricto de la historia, los valencianos (y no solo Mayans) fueron muy críticos, colaboraron con generosidad en el aspecto concreto de la Numismática. Y en este último campo, centraré mi atención en dos colaboradores del agustino: Agustín Sales, cronista de la ciudad y reino de Valencia, y José Ríos, cura párroco de Cullera, cuyos gabinetes confiesa Flórez haber utilizado.

Agustín Sales era teólogo, y con buena formación, hasta opositar a la cátedra de hebreo de la Universidad de Valencia, ganada por Pérez Bayer con el apoyo del arzobispo Andrés Mayoral, del que era secretario. Pero tenía interés por la historia, como confesaba explícitamente. Su primera manifestación en este campo tuvo lugar en 1735. Con motivo de las reformas en la casa profesa de la Congregación de San Felipe Neri, se descubrió una inscripción latina, y la curiosidad de Sales le incitó a copiarla y enviar su trascripción y comentario al deán de Alicante, Manuel Martí, y a Gregorio Mayans, que en el momento era bibliotecario real.

El juicio de Martí lo conocemos por el comentario expresado en carta a Mayans: "Ahí me embía éssa que él llama Disertación sobre no sé qué medalla, y tiene la desgracia que todo lo que ha tomado de mi carta al Sr. Reggio, lo dice al revés. De forma, que parece que no es capaz un hombre de decir tantos disparates ${ }^{19}$. Estas palabras aparecen en la misma carta en que el Deán rechaza anticipadamente la defensa que hizo Sales de la tradición de que el cáliz de la Cena de Jesucristo se conservaba en la catedral de Valencia ${ }^{20}$.

19 M. Martí a G. Mayans, 14-III-1736, en G. MaYans y SiScar, Epistolario III, Mayans y Manuel Marti, edición preparada por A. Mestre Sanchis, Valencia, Ayuntamiento de Oliva, 1973.

20 «Supongo que Vm. conocerá al insigne doctor en theología, Agustín Sales, de Valencia, de quien me hallo el correo passado con essa carta. Este simple está escriviendo sobre la fábula del cuento del Cáliz 
Aunque Mayans veía las deficiencias de la disertación sobre la medalla, y no aceptaba la veracidad de la tradición sobre el cáliz de la Cena, fue mucho más comprensivo; y, por supuesto, quiso realizar una labor pedagógica. Respecto a la moneda e inscripción, sus palabras son un toque de atención sobre los conocimientos requeridos, pues son necesarias muchas lecturas de los «hombres más peritos en este género de letras, quales son Grutero, Reinesio, Fabreto, i poquísimos más. I sin leer a éstos una i muchas veces, no espere Vm. hacer gran progreso en esta materia» ${ }^{21}$.

Y sobre la tradición del cáliz, afirmó que Sales debía haber demostrado la tradición, siguiendo los documentos a lo largo de los siglos, y no basar su criterio en autores modernos. «La disertación del Sagrado Cáliz manifiesta en Vm. una suma aplicación a recoger quanto conduce a hacer verosímil que fue el mismo de la Cena del Señor; pero Vm. se ha fatigado en vano, porque sus mismos fundamentos lo contradicen. Vm. dice que ai tradición i no lo prueva, i de su mismo modo de escrivir se infiere que no sabe el modo de provarla...» ${ }^{22}$.

A pesar de que Sales era un contumaz polemista, como demostró en sus divergencias públicas con el P. Jacinto Segura, autor del Norte crítico (1733), el erudito consiguió ganar la confianza del cronista. Cuando Sales fue nombrado cronista de la ciudad en 1738, recibió la felicitación de don Gregorio pero, además, una serie de consejos prácticos para escribir una historia rigurosa de Valencia. Sales nunca acabó esa empresa (solo quedan papeles sueltos y desordenados) pero colaboró en ambiciosos proyectos mayansianos, tanto en la edición de la Censura de historias fabulosas de Nicolás Antonio (1742) como en la secretaría de la Academia Valenciana fundada por el erudito. Pero, sobre todo, la continuada correspondencia con Mayans creó una sincera confianza y amistad intelectual, al tiempo que agudizó el espíritu crítico del cronista de la ciudad de Valencia, sin que el erudito de Oliva aceptara, ni mucho menos, todos los planteamientos historiográficos de Sales.

En la frecuente correspondencia cruzada entre Mayans y Sales, el erudito comunicaba al cronista: «Parece que el M. ${ }^{\circ}$ Flórez nos provoca a pelea literaria. En lo que a mí toca, lo sé cierto, pues él mismo me lo ha escrito, diciéndome que ha publicado un libro contra la Era española del marqués de Mondéjar i mi Prefación. En quanto a Vm. lo recelo mui mucho, i según lo que me han escrito, creo que impugna a Vm. en su España sagrada. I assí será conveniente que Vm.

de aquella ciudad. Mire Vm. en qué manos lo han puesto. Y me dize, que havía ya dos pliegos impressos. Versantur in tenebris. Es lástima que no nos pongan una coroza».

${ }^{21}$ Mayans a Sales, 13-VIII-1735, A. Mestre SAnchis, Historia, fueros y actitudes políticas, pág. 220.

22 Mayans a Sales, 22-VI-1736, A. Mestre SAnchis, Historia, fueros y actitudes políticas, pág. 221. 
la encomiende i examine lo que dice» ${ }^{23}$. La advertencia del erudito era posterior a la aparición del primer volumen de la España sagrada, pero podía estar fundada en unas palabras de una carta de Flórez en que censuraba la interpretación de una moneda por parte de Sales: y «un tal valenciano, alias erudito, D. Agustín Sales que una medalla, que es indubitablemente de Domitiano, la ha querido explicar como de Augusto, mostrando su nula práctica in re numaria» (5-IV1746). Y el cronista, siempre atento a las noticias literarias, expresó su criterio. Quede Mayans tranquilo, porque si el P. Flórez escribe como en su Clave historial, «le he notado tantas cosas que, si se las saco, le haré eternamente escritor de burla». Y, por supuesto, comprará la España sagrada ${ }^{24}$. La animosidad de Sales era del agrado del erudito de Oliva, que celebraba que hubiese notado la cantidad de errores que contenía la obra del agustino (16-IX-1747).

No hay duda de que esta visión de la actividad historiográfica de Flórez estaba fundada en la lectura de la Clave historial que, de hecho, fue censurada por todos: Mayans, Pingarrón, Asensio Sales, futuro obispo de Barcelona... Sin embargo, pese a sus deficiencias, fue la obra de Flórez más veces reeditada, con complacencia del autor.

Ciertamente Sales compró y leyó la España sagrada. Y no hay duda de que en algún momento pensó responder. Así se deduce de la lectura de unos papeles conservados en el fondo mayansiano del Patriarca ${ }^{25}$. Su título es ya muy expresivo. Ex monumentis apud Flores, tom. III.

Los apóstoles embiaron a España a los VII apostólicos, p. I, XII / Éstos llevaron a los fines de España la fe, p. III / Sepultados cada uno en su ciudad, II, III / Ellos siete llevaron la fée en las partes que predicaron, III, V, VI / En Roma fueron ordenados los 7 apostólicos por los SS. Apóstoles, et ad Hispaniam Gentilem adhuc profecti p. XX, XI, XIX, XXXV / a SS. Apostolis misi in Hispaniam, p. XXII / Sus reliquias antiguas de estos mártires se sabían, p. XXIII / Son los VII Santos confesores, $p$. XXIX / Los VII recibieron la Doctrina (letras ilegibles) i Missa de los Apostoles, $p$. $X X X$ / El Oficio eclesiástico de España concuerda con el Romano $p$. XXX, i en Roma fue siempre aprovado, $p . X X X I /$ Cada uno murió en su ciudad, p. XXVI / Pág. XLV. S. Pablo predicó en España; S. Pedro i S. Pablo dirigieron a España 7 obispos para destruir la idolatría, el orden del Oficio eclesiástico pusieron, i mártires, p. XLI / S. Geroncio de Italia, en tiempo de los apóstoles, p. XLIII / S. Pedro de Braga (Ferreras) discípulo de Santiago, $p$. XLIV / Sn. Ant i Polyx, discípulos de S. Pablo en

\footnotetext{
23 Mayans a Sales, 2-IX-1747, BAHM, 130.

24 Sales a Mayans, 13-IX-1747, BAHM, 27.

25 BAHM, 688.
} 
España, p. XLV, XLVI / Leo III suponit S. Jacobus in Hispaniam non venisse, p. XLVII /Los di(s)cípulos de S. Iago en Jerusalén dexando el cuerpo en Compostela, predicaron en España; quinam? Atanasio i Teodoro, custodios del S. Cuerpo, p. XLVIII / S. Tiago eligió 9 di(s)cípulos (de los muchos) en Galicia; 2 quedaron junto al cuerpo, los 7 discípulos de S. Jaime fueron orden(ados) (en) Roma obispos por S. Pedro i S. Pablo; Innumeris gentilibus illustratori (inter quos Indalecio Valencia) Cada uno murió en su sede, Torq(uato) etc. p. XLIX / S. Jaime no vino a España, deducis p. LVII / Traslación de su cuerpo LVII, XLVII / Invención de su cuerpo p. LVIII. Era MCVII. Lex Toletana reiecta, Romana recepta, p. LXV / Nra. Sra. del Pilar a Fac. Apostol. Calixto III, p. LXXV.

He querido transcribir el texto como lo escribió Sales. Puede observarse que se trata de toda la versión de Flórez sobre los orígenes de la cristiandad hispana, con todas las tradiciones jacobeas, la del Pilar y los Varones Apostólicos. El cronista de Valencia organiza los temas en varios apartados: los Varones Apostólicos, que fueron consagrados obispos en Roma por san Pedro y san Pablo y enviados a España, la venida de san Pablo y de Santiago a España (aunque también cita el dato de que León III no creía que Santiago viniera a España), los discípulos de Santiago, de los que unos permanecen en Compostela y otros fueron a Jerusalén, y la Virgen del Pilar.

Pero la paginación adjunta a cada uno de los temas no corresponde a las páginas del volumen III de la España sagrada, que, además, están en números arábigos. Probablemente corresponderían a algún volumen de su biblioteca, que ha sido imposible encontrar; porque la biblioteca de Sales fue adquirida, a su muerte, por el arzobispo de Valencia en 1774, e incorporada a la del prelado. Solo la correspondencia con Mayans, que le fue entregada al erudito, y muy pocos volúmenes de papeles manuscritos se conservan en el fondo mayansiano del Colegio del Patriarca (ванм) ${ }^{26}$.

Que Sales no aceptaba todas estas tradiciones podemos deducirlo de las dificultades que tuvo entre los clérigos valencianos de su tiempo por su crítica sobre tradición de la Virgen del Pilar, expuesta quizá con excesiva vehemencia en conversaciones privadas. También aparece la referencia a san Rufo, supuesto obispo de Tortosa y discípulo directo de san Pablo en su visita a España (que por supuesto negaba), de quien habló con Mayans en 7 de septiembre de 1764. Pero de la réplica dura e inapelable, de que hablaba en la carta a Mayans, no he encontrado documentación seria y fundamentada; solamente se conservan datos

26 Sobre el asunto, A. Mestre SAnchis, Los ilustrados, el origen de la imprenta y el catálogo de los incunables españoles, Valencia, Generalitat, 2007, págs. 38-39. 
deshilvanados y sin referencia concreta. Sin embargo, en asunto de monedas, la actitud con Flórez fue mucho más generosa, como veremos.

El segundo personaje, José Ríos, es prácticamente desconocido, y su relación con Flórez queda limitada al intercambio de monedas. Sin embargo, hay un hecho claro: era amante del humanismo latino y poseía un gran tesoro de monedas antiguas. Con fama de predicador, fue criticado por Manuel Villafañe, del círculo de Bayer y años después Consejero de Castilla, por sus excesivas florituras literarias, y pensaba aconsejarle la lectura de El orador christiano de Mayans. Pero el erudito le disuadió, como dice el mismo Villafañe, pues «según Vm. me cuenta, es cereus in vitrum flecti, monitoribus asper» ${ }^{27}$.

La duplicidad de carácter se puede observar en algunos datos que conocemos. José Nebot, abogado abierto a la ciencia moderna, comenta en sus cartas a Mayans que en 1744 Ríos mantuvo una larga discusión con el Dr. Andrés Piquer sobre las razones de mantener a Cicerón como modelo de latinidad, como defendía Piquer, y no al papa san León, como defendía Ríos. La discusión, anota Nebot, se prolongó de 10 a 12 de la noche ${ }^{28}$. En contraste, las palabras de Martínez Pingarrón ante la visita de Ríos a la Biblioteca Real, muestran la otra faceta de Ríos: amable, hábil dialogante: «Ayer me buscó en la bibliotheca el rector de Cullera, me dio mil abrazos de parte de Vmd., cuya carta dijo me trahería. Hablamos largamente de varias cosas. Me pareció un sugeto docto, de gran juicio i penetración, i mui astuto en el conocimiento de Corte, que parece la ha cursado toda su vida. Nos trataremos más despacio, i si pudiere servirle en algo lo haré como por Vmd.» ${ }^{29}$.

Ríos debió estar muy vinculado a la Compañía, pues predicó sermones sobre san Ignacio y pronunció discursos en la casa profesa de los jesuitas de Valencia; y, sobre todo, después de la expulsión de los padres de la Compañía, tuvo problemas eclesiásticos, con seguridad por asuntos de escuelas teológicas. Pero no hay duda de que era un experto en numismática, como consta por su trabajo Apuntes sobre numismática y paleografía, conservado en la Biblioteca Universitaria de Valencia. Y solo en este aspecto entró en relación con Flórez, si bien, como en el caso de Sales, fue más tardíamente.

\footnotetext{
27 Villafañe a Mayans, 31-VII-1743, G. MaYans y Siscar, Epistolario, XIV, pág. 303.

28 Nebot a Mayans, 7-X-1744, G. Mayans y Siscar, Epistolario, XXIII.

29 Martínez Pingarrón a Mayans, 7-V-1757, Epistolario, VIII.
} 


\section{La fecunda colaboración con Flórez}

En contraste con la nula receptividad ante las solicitudes de Panel, los valencianos colaboraron generosamente con Flórez. Si bien las palabras de Martínez Pingarrón, que hablaba del gran tesoro de monedas que poseía el agustino, son de 1746, los poseedores de monedas antiguas, al menos los valencianos, tardaron en comunicarle sus monedas. Puede que el retraso radique en las divergencias Flórez-Mayans, después de la colaboración y posteriores diferencias respecto a la Era Hispánica y las tradiciones jacobeas. Pero, de hecho, es menester confesar que el agustino empezó a preocuparse de manera intensa en el asunto de las monedas antiguas a partir de 1750. El 24 de octubre de ese año, Flórez escribía a Mayans: «Tengo noticia que Vmd. se halla con dos medallas de Segobia, si es así, le declaro mi atrevido pensamiento de ver una. Mas, si no la tiene duplicada, le estimaré una copia ${ }^{30}$.

El erudito de Oliva contestó con noticias verdaderas, y si bien con sus palabras evitaba compromisos, daba pistas para que el agustino pudiese encontrar las monedas deseadas. «Sepa V. Rma. una historia. D. Juan Ruberti, teniente del Regimiento de Bravante, se entretuvo en dibujar todas las monedas españolas que pudo ver originales, o ya dibujadas en libros. Me pidió las que yo tenía, i se las franqueé, i en agradecimiento me regaló un librito en octavo con todos los borradores de los dibujos que avía hecho. Lo supo el barón de Beniparrell, D. Pasqual Escrivá, me pidió prestados los dibujos i cinquenta i quatro monedas españolas, le hice este gusto, i él a mí el disgusto de no averme querido bolver ni el libro, ni las monedas. Si entre éstas se hallava alguna de Segovia, no me acuerdo. Lo cierto es que no la tengo. Pero tengo sospecha que dichas monedas i dibujos paran en poder del P. Panel, i en todo caso es cierto que D. Francisco Pérez Bayer regaló al padre Panel el libro i monedas que compró de D. Juan Ruberti. Yo quisiera tener la medalla que V. Rma. me pide, para embiársela al instante en prueva del deseo que tengo de servir a V. Rma.» (31-X-1750).

Mayans decía la verdad, y las cartas de Ruberti al erudito, con las noticias de los hallazgos de monedas cerca de Oliva, en Nules, Tortosa y otras ciudades catalanas, se encuentran en el Archivo de la ciudad de Valencia, Fondo Serrano Morales. También es cierto que, a partir de ese momento, Flórez acelera sus trabajos sobre Numismática y encuentra los dos colaboradores importantes de que venimos ocupándonos. No puedo evitar la sospecha de que Burriel sirvió de enlace entre Sales y Ríos con Flórez, conociendo los favores que el jesuita hizo

30 Todas las citas de la correspondencia directa entre Flórez y Mayans, así como la de Flórez-Agustín Sales, están publicadas como apéndice documental en A. Mestre SAnchis, Historia, fueros y actitudes políticas. 
al agustino, desde colaboraciones intelectuales a favores político-económicos, por medio del P. Rávago. Por lo demás, Burriel conocía el interés de Flórez por la Numismática: «El P. maestro Flórez — decía en carta a Mayans— es hombre dignísimo de ser ayudado y fomentado en sus estudios y designios por todos los bien intencionados, y me alegro que $V m d$. lo haga así... Ha recogido un número prodigioso de libros antiguos y modernos, tiene un monetario prodigioso que cada día aumenta considerablemente...» (30-IV-1746, pág. 253).

El jesuita conocía bien a Sales y había colaborado en difundir en la corte la inscripción latina, hallada en Sagunto y trascrita, comentada e impresa por el cronista de Valencia. Y, respecto a Ríos, son explícitas las palabras de Mayans. El erudito habló a Burriel de Ríos, el jesuita pidió copias de monedas e inscripciones que el cura de Cullera le envió; más aún, don Gregorio le agradece que le deje ver las que envía a Toledo para Burriel ${ }^{31}$.

Solo así adquieren una explicación coherente las palabras del mismo Flórez a Mayans: «Yo estoi disponiendo un libro de Medallas de colonias y municipios de España, con todas las publicadas e inéditas que tengo y han llegado a mi noticia. Si Vd. tuviera alguna inédita, le estimaré el divujo para que la cosa sea más completa. De esse reino contribuyen el Dr. Ríos i Sales. Si Vd. conociere algún amigo, que pueda dar copia de algo inédito, hará un servicio al público en su influjo» (23-III-1755). La respuesta de Mayans confirma las noticias que había dado con anterioridad: disipó las que tenía, que regaló a Martí, Bayer, Jover y «Pasqual Escrivá me pidió todas las españolas, que yo estimava más, y en su muerte desaparecieron» (29-III-1755).

Estas palabras encuentran eco en las cartas de Flórez a Sales. Valgan, como ejemplo, las siguientes: «Las medallas de Escrivá se han vendido aquí, a lo menos corrían con esse nombre. De España no tenía cosa notable lo que vino acá. El Sr. Mayans me avisó haverle prestado algunas que no estavan entre las que vinieron, puede ser que las tenga reservadas la Sra. viuda». Y continúa pidiendo monedas: tiene en Sagunto quien se preocupa de los descubrimientos, en Liria se interesa el propio duque, y si algunos clérigos doctos que hay en Valencia le quisieran favorecer... (s. f., a finales de 1754).

Pero, de hecho, Sales había colaborado con generosidad. Envió una inscripción arábiga, que Flórez entregó a Casiri para su traducción (9-V-1754; 29VI-1754) y, por medio de un clérigo (José Salelles) le envió un buen lote de monedas que devolvió Flórez con delicadeza. Bien merecen la trascripción unas palabras del agustino, aunque la longitud y precisión de los datos no aconsejan la copia completa: «Acerca de medallas antiguas es phenómeno nunca visto lo

$31 \quad$ Mayans a Ríos, 4-III-1752, BAHM, 150. 
que Vmd. menciona de Lugo. Recelo sea medalla Legionaria, si es legítima del tiempo anterior a Claudio. Por esto me alegrara que, pues es cosa fácil y no se pierde nada, se sirviesse Vmd. remitir las 82 españolas, a fin de tener el buen rato de verlas en sí mismas, pues Salelles las podrá devolver y yo agradeceré a Vmd. el gusto que me dará en verlas... Pero de cosa no batida en España, no tengo codicia, y assí, si Vmd. gustare que yo vea luego, sean sólo las de España, porque tengo empezado un libro de Colonias y Municipios de España, i deste fin deseo ver o adquirir quanto pueda» (20-VII-1754).

En efecto, por medio de José Salelles, Sales envió a Flórez un buen lote de monedas y, si bien el agustino no especifica la calidad de las 82 españolas, confiesa el gusto que ha tenido con la vista de algunas monedas: una Legionaria de Ilici, otra de Nero y Druso de Cartagena, una moneda Rodas gaditana, «bien rara; la que se escribe de León, o Legionaria, es de Mérida, dos que se apuntan de Cascante, la una es de Sagunto, muy buena, que no está entre las intituladas de Sagunto, y es de Sempronio Gémino. Entre las 12 españolas de Sagunto, hay un As romano con la Nave, y cabezas de Jano en gran bronce...». Y, por supuesto, Flórez se ofrece a intercambiar monedas que puedan completar sus respectivos monetarios ${ }^{32}$.

Menos datos poseo de José Ríos, pues carezco de cartas cruzadas entre Flórez y el cura de Cullera. Solo la correspondencia entre Mayans y Ríos permite acercarnos, y de manera muy remota y parcial, al conocimiento de la aportación del párroco de Cullera a la obra numismática de Flórez.

No hay duda de que había muchos puntos culturales en que Mayans y Ríos sintonizaban, entre los cuales sobresalen el humanismo, la historia y, por supuesto, la Numismática. Ríos se permitía escribir en latín al erudito, como hizo al celebrar la Carta al pavordre Vicente Calatayud, en que Mayans censuraba la repulsa del pavorde al humanismo (Manuel Martí), la crítica histórica (Nicolás Antonio) y la filosofía moderna (Tosca). Ríos llamaba a Calatayud el anticrítico, mientras alababa la erudición de don Gregorio ${ }^{33}$. También censuraba Ríos las burdas ficciones del llamado Sacristán de Pinos, que rememoraba las supuestas reliquias del Sacromonte. Pero, sobre todo, mantuvieron frecuente intercambio epistolar sobre monedas antiguas, tanto antes como después de la colaboración concreta de Ríos con Flórez, de la que sabemos poco.

El cura de Cullera, al parecer, visitaba Madrid con cierta frecuencia, o su visita fue muy larga. En 1757 pasó por la Biblioteca Real y saludó a Martínez Pingarrón que manifestó su sorpresa ante la habilidad con que Ríos se desen-

32 Flórez a Ag. Sales, 24-VIII-1754, A. MEstre, Historia, fueros y actitudes políticas, págs. 580-581.

33 Ríos a Mayans, 15-II-1761, en BMV, Serrano Morales, 6811-II. 
volvía en la corte. Y en 1758, Ríos confesaba a Mayans que durante su residencia madrileña había comprado «muchas y exquisitas medallas de todas series, que a merced de canjear y mendigar, junté, y quedan a su disposición». Estando en la Corte, supo que se vendieron en Valencia «522 monedas familiares, imperiales y españolas antiguas en la mayor parte todas de plata» y lamenta que un amigo suyo no las quisiera comprar.

Pero en esa carta a Mayans del 26 de julio de 1758, escribe estas clarificadoras palabras: «El maestro Flórez parió a bien en dos tomos mucho bueno de nuestras colonias y municipios. No es que yo en todo vaya conforme; pues, aunque en algunos puntos ha retra[c]tado por mi esfuerzo lo dicho en su España, en otros ha seguido y publicado contra mi parecer. Me regaló la obra, que queda a su disposición, y muchas medallas de singular aprecio, que Vm. verá y dispondrá de ellas $»^{34}$.

Parece cierto que habló en Madrid con Flórez. ¿Le enseñó parte de su monetario? ¿Canjeó monedas con el agustino, como dice haber hecho en la corte? Desconocemos datos concretos de la colaboración de Ríos con el agustino, y este testimonio es clarificador. Por lo demás sabemos, por confesión suya posterior, que continuó en relación con Flórez.

El erudito de Oliva celebró, por supuesto, la adquisición de monedas en Madrid por parte de Ríos: «Vm. es el único que ha buelto de Madrid a su casa con monedas»; y deja constancia del intercambio de monedas: «Estimo las dos monedas de plata españolas, i de caracteres desconocidas, por ser únicas de plata que tengo de este género; pues, como ya dige a $\mathrm{Vm}$., me hurtaron las que yo tenía con gran sentimiento mío». Y después de confesar que ya recibió las que le devolvía el cura de Cullera, le ofrece «siete de plata romanas, ochenta i quatro de cobre, muchas de las quales aún están cubiertas de la tierra, que las iva consumiendo, i veinte i quatro españolas de cobre». El ofrecimiento del erudito era sincero: Ríos podía disponer libremente de ellas, pues «yo no apetezco sino las desconocidas de España i nuestras colonias i municipios». Y, respecto a las noticias sobre las conversaciones de Ríos con el agustino, se limita a decir, con cierta despreocupación, que ha comprado la última obra de Flórez, «que aún no he tenido tiempo de leer, porque estoi mejor empleado en asunto que confío será del gusto de $\mathrm{Vm}$. i servicio de Dios» ${ }^{35}$.

Ríos, además de enviar al erudito su Disertación sobre una inscripción latina hallada en Liria, donde había sido vicario durante 15 años, lamenta la dificultad de adquirir monedas en Valencia: «Apenas [a]parece ya moneda al-

\footnotetext{
34 BAHM, 52.

35 Mayans a Ríos, 23-VIII-1758, BAHM, 159.
} 
guna; hierve el mundo de emisarios para Madrid y Toledo. Flórez me ha prometido algunas griegas que deseo. Del Imperio Bajo ya tengo, pero para nada aprovechan». Se trata de una carta del 12 de agosto de 1760. Ríos continuaba enriqueciendo su tesoro de monedas, en parte gracias al intercambio, que queda probado por el hecho de que dos años después de su viaje a la corte el agustino continúe enviándoselas, y gracias a su fama de buen anticuario.

En un momento pensó regalar su monetario a un monasterio cartujo. Pero el arzobispo Mayoral, que había fundado la primera biblioteca pública en Valencia, pensó ampliarla con unas salas dedicadas a numismática; así lo comunicaba el prelado al erudito de Oliva: «Al presente lleba bastante atención el Museo i Monetario (fruta del tiempo i moda) se pondrá en pieza separada, porque tengo terreno a satisfacción, que antes no tenía. El cura de Cullera y D. Francisco Pérez [Bayer] han tomado por su cuenta este ramo de la bibliotheca, que han enrequecido [sic] con millares de monedas; continuamente entran de otras partes, i ayer una caja de ellas de la Cartuja de Segorbe. Yo nada, nada, entiendo ${ }^{36}$. Y, en plena lógica, pidió el monetario a Ríos.

Pero el cura de Cullera no solamente participa la noticia a Mayans, sino que le explica el sistema de ordenamiento que realiza en la biblioteca arzobispal. Divide las monedas en 4 partes: 1) Roma-República; 2) Las imperiales; 3) Colonias y municipios; 4) Varios reinos y otras antigüedades ${ }^{37}$. También realiza una breve alusión al ritmo de su trabajo: «Ya dige a Vm. que ofrecí al público mis medallas, que estoy arreglando. Traté de las familiares; voy ya con las Imperiales, y estoy en M. ${ }^{\circ}$ Aurelio. Apenas siento la pluma ${ }^{38}$. Y en la biblioteca de Palacio Arzobispal permaneció el monetario al servicio del público hasta la invasión napoleónica, que convirtió las monedas en un montón de plata.

Aparte de los matices de negatividad, o de colaboración, podemos observar dos proyectos de edición de monedas antiguas. Uno, propiciado y dirigido por Panel, el jesuita francés protegido por los PP. Confesores del monarca (Clarke y Le Fèvre) y encargado del monetario de los hijos de Felipe V. Otro, promovido por el agustino P. Flórez que cristalizó en la edición de Medallas de las colonias, municipios y pueblos antiguos de España.

Por los testimonios de personas cercanas y allegadas a Panel, el proyecto existía y tenía visos de prosperar. Martínez Pingarrón lo expresaba con claridad: «De quatro semanas a esta parte no he podido escrivir a Vmd., porque empleé las tres primeras en traducir en castellano una disertación en forma de carta

36 A. Mayoral a Mayans, 28-X-1763, G. MaYans y SiSCar, Epistolario, XXIV, Mayans y los arzobispos de Valencia... Edición preparada por A. Mestre Sanchis, Valencia, Ayuntamiento de Oliva, 2009.

37 Ríos a Mayans, 28-X-1763; BMV, Serrano Morales, 6811-II.

38 2-I-1765, MV, Serrano Morales, 7281-69. 
latina del P. Panel sobre unas medallas, por avérmelo pedido él i un theniente capitán agregado a esa plana mayor, que vive en Morviedro (aunque ahora se halla aquí) i se llama Dn. Juan Francisco Ruberti. Quieren imprimirla i entonces la tendrá Vmd. i si se arrepintieren i pasare algún tiempo, no carecerá Vmd. de ella, que tiene veinte i dos pliegos de mi letra» (9-VIII-1747).

Más claras y precisas son las palabras de Burriel, allegado por tantos conceptos al jesuita francés. Miembros ambos de la Compañía y residentes en la misma comunidad, Burriel intercedió ante sus amigos (desde Mayans a Ríos y Sales) para que proporcionaran monedas a Panel. Cuando el Cardenal-Infante se secularizó, la misión de Panel quedó centrada en coleccionar monedas, como pudimos ver en las cartas de Burriel a Mayans. Y con toda claridad aparece que, con el favor del P. Confesor, Panel estaría dedicado a la colección de monedas: «Que el Infante-Cardenal no quiere estudiar más y su madre ha dicho al rey que le ha menester a su lado para su consuelo. Con esto el P. Panel está desocupado ya de sus lecciones y solo cuidará del Gavinete de Antigüedades porque tampoco da lección a la Infanta. El rey ha hecho lo posible porque no sea sí, pero sin fruto. Mostrando al rey el P. Panel unas ideas de medallas para la coronación [...]» (30-VII-1746).

En esa línea de la idea de que Panel preparaba la colección de monedas, se explica el temor de Pingarrón de mostrar al jesuita la traducción de la Ciencia de las medallas. He aquí las palabras de Burriel: «Conozco la feble de el amigo Pingarrón, que sin duda es que, haviéndole yo dicho que quería ver la obra ahora para hacer un epítome de ella que dar a mis muchachos, porque pudiesen dar alguna razón de sus conclusiones esta primavera, él havrá creído que se estancaría eternamente en mí y que yo le detendría su impresión o tal. Recatarse porque yo no lo diga a Panel no lo creo, porque como yo he callado que la hacía, callaría que la ha hecho» (11-II-1747).

Es posible que la razón estuviera en la sospecha de la colaboración con Panel, que el joven jesuita no creía. Porque el temor de Pingarrón frente a la actitud crítica de Panel contra Mayans y otros era evidente: «No causa instancia [Panel], aunque tiene muchos que le adulan que son de su mismo calibre, i tira a hacer partido. Temo que le dé la piedra en los pies. Yo le trato con toda urbanidad i le sirvo en lo que me pide; es preciso sacar salud de nuestros propios enemigos» (28-I-1747). Por lo demás, las frecuentes alusiones a las monedas que iban destinadas a Madrid y a Toledo, y la solicitud de monedas por parte de Burriel a los valencianos, hizo sospechar que estaban destinadas a perfeccionar la colección de Panel. A las referencias de Pingarrón y de Burriel, podemos añadir unas palabras del mismo Flórez en el mismo sentido, lo que demuestra que los hombres de letras creían que Panel preparaba una edición de monedas 
españolas antiguas. Hablando de la necesidad de publicar una buena colección de monedas antiguas, de las que posee una enorme cantidad, y de cuyos conocimientos necesitan los jóvenes estudiosos, escribía el agustino a Mayans: «Añádese el que me tira mucho la contraposición de Panel, y, si se tarda mucho, y yo puedo concluir mi Geografía Eclesiástica para el año que viene (pues lleva ya ocho años) será en esto mi primera atención, pues tengo buena porción de monedas inéditas respectivas a España» (5-IV-1746, pág. 449).

¿Por qué fracasó el proyecto de Panel? En principio, parecía tener todos los apoyos necesarios favorables: el P. Confesor jesuita (Le Fèvre y después Rávago), el apoyo de Burriel con enorme influencia cultural y política en el momento... Y, sin embargo, el proyecto, si llegó a formularse con seriedad, constituyó un fracaso.

Es preciso tener en cuenta que toda la actividad de Panel en España fue un planteamiento político. Martínez Pingarrón lo vio con absoluta claridad desde el primer momento: «Tiempo ha que los cortesanos internos pensaron en destruirse con sagacidad, cautela i silencio; esto es, los franceses a los italianos; tomaron sus medidas i juzgaron preciso un anticuario para esta bibliotheca que fuesse jesuita, i hicieron llamar al P. Panel, francés, que, aunque tardó en llegar, vino, i el rei le nombró por segundo preceptor de los señores Infantes i por su anticuario, mandando que se le franqueassen las antigüedades etc., que ai en esta biblioteca, en la que ha estado reconociendo i empezando a trabajar como tres semanas, i después ha seguido la Corte» (17-VIII-1742).

Desde ese momento, Panel tenía un frente de oposición en la Real Biblioteca. Y pronto se hizo visible. Nasarre encargó a Pingarrón la traducción de la Ciencia de las medallas del jesuita francés Louis Jobert, con la finalidad de demostrar que en España también había entendidos en Numismática. Además de la traducción, con su largo prólogo, la intención inicial quedaría clara con el manuscrito de Pingarrón conservado con el título de Disertación sobre la Ciencia de las Medallas, en la que se describen las obras de los tratadistas españoles sobre la Numismática ${ }^{39}$. Y los datos aportados por el bibliotecario real constituyen el testimonio de una actitud de reserva y de velada oposición a la actividad cultural y numismática de Panel.

Un segundo frente contrario a Panel procedía de Valencia. En 1743, el jesuita francés visitó Valencia; dado que buscaba monedas y el erudito poseía la mejor colección, Agustín Sales le previno ante una posible visita y solicitud de monedas antiguas. Por unas palabras posteriores de Pingarrón, podemos dedu-

39 Francisco Aguilar Piñal, Bibliografía de autores españoles del siglo XVIII, Madrid, CSIC, vol. V, a la voz Martínez Pingarrón, ref. 3522. 
cir que Panel no perdonaba la crítica que había hecho don Gregorio del método de Harduin en la interpretación de monedas. Así se expresaba el bibliotecario real: «El P. Panel grita contra Vmd. por lo que dice del P. Harduino en la vida del P. Mariana. Supongo que hace lo mismo contra todos quantos no son harduistas o panelistas. No causa instancia, aunque tiene muchos que le adulan que son del mismo calibre, i tira a hacer partido. Temo que le dé la piedra en los pies. Yo le trato con toda urbanidad i le sirvo en lo que me pide; es preciso sacar salud de nuestros propios enemigos» (28-I-1747). Y mucho esfuerzo debió costar a Pingarrón, que se vio desplazado del cuidado de las monedas en la Real Biblioteca, controlada por Panel.

A todo esto, es menester añadir que Panel no tenía entidad cultural. Bayer, que lo recibió en Valencia con entusiasmo, y supo aprovecharse de su influencia en las altas esferas políticas, confesaba en su carta a Mayans: «muy suelto en el latín, pero no me parece igualmente culto» (19-VI-1743). Y el mismo Burriel, su panegirista, acabó reconociendo que el jesuita francés no era hombre para grandes empresas (como la historia de la catedral de Toledo, que esperaba promocionase). Tampoco ayudó a Panel el bajo nivel de sus publicaciones. Martínez Pingarrón había trabajado en la traducción de un trabajo de Panel (ayudado de Ruberti) de 22 pliegos (9-VIII-1747). En 1749 enviaba al erudito de Oliva una serie de libros: Franckenau, el Viaje de Jerusalem del marqués de Tarifa con el Poema de Joan del Encina, «las Disertaciones del P. Panel (por el qual libro siento pague Vmd. veinte i seis reales, pues no los merece i assí no se han vendido una docena» (1-I-1749).

Y, si Mayans decía el 17 de octubre de 1750 al bibliotecario real: «Me escriven que los italianos han hecho mucha burla del P. Panel», apenas dos años después, Pingarrón comentaba los datos que le habían llegado desde Italia: «El artículo del Diario de Italia sobre la Dissertación de Panel está mui fuerte. Un amigo mío me lo embió de Roma por el correo, i le tengo casi traducido. Todo se pondrá a la colada» (6-V-1752).

Por lo demás, no podemos olvidar que en 1754, cuando Flórez acelera el trabajo sobre las Medallas de las colonias, municipios y pueblos antiguos de España y empieza a recibir las colaboraciones de Sales y de Ríos, las circunstancias políticas habían cambiado. Y, si la llegada de Panel fue una jugada política, también la política incidió negativamente en los proyectos del jesuita francés, y, en contraste, favoreció, si cabe, la culminación del trabajo del agustino español. De hecho, la muerte de Carvajal, el destierro de Ensenada y, consecuencia lógica, la destitución de Rávago como confesor de Fernando VI, privaban a los jesuitas del dominio cultural en los órganos de poder. Ya sabemos que, con la llegada de los manteístas al gobierno, hasta el mismo Burriel se vio impedido de 
llevar a buen término sus meritorios trabajos en la Comisión de Archivos. Si Panel continuaba en sus ideas y proyectos, la edición de monedas e inscripciones antiguas era a todas luces inviable.

Otra cosa era el proyecto de Flórez. El agustino, aparte de su Clave historial, de nulo valor histórico, había empezado a publicar la España sagrada (1747), llevaba varios volúmenes impresos en que defendía calurosamente las tradiciones eclesiásticas más valoradas a nivel nacional (la venida de Santiago, Virgen del Pilar, varones apostólicos...) y había recibido reconocimiento y subvenciones del gobierno. Todo, conviene decirlo, por influencia de Burriel y del P. Confesor Rávago, ambos jesuitas. Y el mismo Flórez confiesa que tenía la ayuda económica del Gobierno para la empresa de publicar las Medallas: «Yo estoy ya disponiendo abrir las láminas de las medallas de España, por quanto el rey me socorrió con mil pesos para la obra, que passa de los dos mil». Son palabras del mismo Flórez a Agustín Sales de 22 de febrero de 1755. Y no conviene olvidar que, en esas fechas, los manteístas ya controlaban el gobierno de Fernando VI.

Con la edición de Medallas de las colonias, municipios y pueblos antiguos de España, Flórez dio un gran impulso al estudio de la Numismática en el siglo XVIII español. 